\title{
Los recursos forestales en APEC, una visión ambiental y económica
}

$\mathrm{E}$ 1 impacto de las actividades humanas sobre el medio ambiente es cada vez mayor. Por ello es necesario que la conservación de los recursos naturales, incluida la diversidad biológica, sea asunto de pronta atención, no sólo al interior de los países, sino como un asunto global. Es de sobra conocido que muchas de las catástrofes ambientales dejan sentir sus efectos más allá de las fronteras nacionales. Conscientes de lo anterior, las economías que integran el Foro de Cooperación Económica de Asia Pacífico (APEC), han incluido desde la reunión de Seattle (1993) temas ambientales en su agenda. El informe producto de este encuentro acordó tomar medidas para «proteger la calidad del aire, agua, espacios verdes y el correcto manejo de los recursos energéticos y renovables para asegurar un crecimiento sostenible y proporcionar un futuro más seguro para nuestras gentes». Posteriormente en el encuentro de Osaka, Japón en noviembre de 1995, se confirmó la integración del ambiente y el desarrollo sustentable dentro de las actividades de APEC. En 1997, los líderes de APEC acordaron en Vancuver, Canadá, que la «realización del desarrollo sustentable sería el corazón de los mandatos de APEC ${ }^{1 / 6}$

Los líderes de APEC, han mostrado su interés por llevar a cabo trabajos conjuntos en áreas relacionadas con el medio ambiente, por lo que es importante analizar uno de sus principales elementos como lo es el de los recursos forestales, el cual tiene, además de una función económicamente significativa, funciones esenciales para la vida, como son: favorecer la infiltración del agua de lluvia a los mantos fréaticos, proteger el suelo contra la erosión, como refugio y alimento de la fauna silvestre, la conservación de la biodiversidad biológica, y la

* Pasante de la Licenciatura en Estudios Internacionales ORCID http://orcid.org/0000-0002-4553-8141 posesión de valores estéticos recreativos y culturales ${ }^{2}$.

Otros de los motivos para analizar este recurso natural en el marco de APEC, es que las economías que conforman este grupo disponen de la mayor extensión de cubierta forestal del mundo y de los principales comercializadores internacionales de madera (con excepción de Brasil). Por ello, este artículo tiene el objetivo de proporcionar una visión general sobre los recursos forestales en APEC en dos vertientes: la ambiental y la económica.

\section{Los recursos forestales de APEC en el contexto mundial}

La extensión territorial mundial consta de 131,396.18 km2, de los cuales sólo 30 por ciento comprende zona forestal. Los bosques tropicales y subtropicales ocupan 56 por ciento de la superficie forestal mundial y los bosques templados y boreales el 44 por ciento. El territorio de las economías de APEC representa el 46 por ciento de la superficie territorial global, pero posee más de la mitad de la superficie forestal del planeta, lo que la convierte en la región con mayores recursos forestales del mundo y con la mayor comercialización de tales productos $^{3}$

Los países con mayor extensión forestal son, Rusia, Canadá y Estados Unidos, seguidos por China, Australia e Indonesia (juntos poseen 87 por ciento de la superficie forestal de APEC). El país con menos superficie forestal es Singapur (2 hectáreas). Los países que tienen mayor superficie forestal en proporción con su tamaño son Brunei, Papua Nueva Guinea, Japón, Corea, Malasia, Indonesia, Perú y Rusia. Para Rusia e Indonesia la superficie forestal es un factor abundante. 
Cuadro 1

La superficier forestal en las economías de APEC: 2000

\begin{tabular}{|c|c|c|c|}
\hline Economías & $\begin{array}{l}\text { Extensión territorial } \\
\text { (miles de hect.) }\end{array}$ & $\begin{array}{l}\text { Superficie forestal } \\
\text { (miles de hect.) }\end{array}$ & $\begin{array}{l}\text { Superficie forestal } \\
\text { por economía (\%) }\end{array}$ \\
\hline Malasia & 32,855 & 19,292 & 58.7 \\
\hline Brunei & 527 & 442 & 83.9 \\
\hline Australia & 768,230 & 154,539 & 20.1 \\
\hline Canadá & 922,097 & 244,571 & 26.5 \\
\hline China & 932,742 & 163,480 & 17.5 \\
\hline Chile & 74,880 & 15,536 & 20.7 \\
\hline Corea & 9,873 & 6,248 & 63.3 \\
\hline Estados Unidos & 915,896 & 225,993 & 24.7 \\
\hline Hong Kong & 100 & n.d. & n.d. \\
\hline Japón & 37,657 & 24,081 & 64.0 \\
\hline México & 190,869 & 55,205 & 28.9 \\
\hline Nueva Zelanda & 26,799 & 7,946 & 29.7 \\
\hline P.Nueva Guinea & 45,240 & 30,601 & 67.6 \\
\hline Indonesia & 181,157 & 104,986 & 58.0 \\
\hline Perú & 128,000 & 65,215 & 50.9 \\
\hline Tailandia & 51,089 & 14,762 & 28.9 \\
\hline Singapur & 61 & 2 & 3.3 \\
\hline Vietnam & 32,549 & 9,819 & 30.2 \\
\hline Rusia & $1,688,850$ & 851,392 & 50.4 \\
\hline Taiwán & 1,400 & n.d. & n.d. \\
\hline Filipinas & 29,817 & 5,789 & 19.4 \\
\hline Total regional & $6,070,688$ & $1,999,899$ & 32.9 \\
\hline Total mundial & $13,139,618$ & $3,869,453$ & 29.5 \\
\hline $\begin{array}{l}\% \text { de la cubierta } \\
\text { forestal regional }\end{array}$ & 386,453 & $1,999,899$ & 51.7 \\
\hline
\end{tabular}

De los ocho países con mayor extensión forestal en proporción con su tamaño, Brunei, Japón y Corea se caracterizan por la existencia de un control muy estricto en el manejo de los bosques y por satisfacer su demanda a través del mercado exterior. Lo que diferencia a estos tres países es, primero, que Japón es un importante consumidor de productos madereros y productos de papel; el país tiene una amplia industria procesadora de este recurso, por lo que recurre a la importación de grandes cantidades de materia prima. Segundo, en Corea una elevada proporción de los bosques son el resultado de programas de repoblación forestal en gran escala, ya que este país sufrió una grave degradación a causa de los diversos conflictos bélicos durante el siglo XX; de hecho la masa forestal aumentó 2.3 millones de hectáreas a consecuencia de esta política forestal; en la actualidad posee una importante industria de la transformación de la madera, aunque ésta se basa principalmente en madera importada. Por último, Brunei no cuenta con industria maderera sofisticada, sólo produce cantidades modestas de aserrato para el mercado nacional $y$ el resto se satisface mediante importaciones ${ }^{4}$

Por otro lado, Malasia, Indonesia y Papua Nueva Guinea explotan sus recursos forestales a través de una organizada infraestructura maderera enfocada principalmente a la exportación, que les reditúa, según datos de 1998, un superávit comercial forestal de 7,545 millones de dólares (suma de los tres), e incide de manera importante en la economía nacional. 
Por su parte, Rusia es el mayor productor y exportador de madera en rollo industrial del mundo. En este país los bosques están en manos del Estado, mientras que la industria maderera, en las del sector privado. Esto le ha permitido al gobierno, por un lado, mantener el control en el manejo de los recursos forestales y, por el otro, eficientar la industria, la cual se refleja en el amplio superávit comercial que tiene con el exterior (2,255 millones de dólares en 1998).

En el caso de Perú las cosas son completamente diferentes. A pesar de que más de la mitad de su territorio se encuentra cubierta de recursos forestales, no cuenta con una eficiente industria maderera, lo que lo ha llevado a la irónica situación de importar grandes cantidades de madera, que se refleja en el déficit comercial en este rubro, que tan sólo en 1998, fue de $\$ 135$ millones de dólares su saldo negativo. Por cierto, en este país la madera constituye una importante fuente de combustible.

Continuando con los seis países con mayor superficie forestal en APEC, podemos afirmar que se caracterizan por ser grandes productores de productos maderables y los mayores

Cuadro 2

\section{Comercio forestal: 1998}

\begin{tabular}{lr}
\hline Países & $\begin{array}{r}(\mathrm{X}+\mathrm{M}) \text { millones de } \\
\text { dólares }\end{array}$ \\
\hline Indonesia & 6,091 \\
Australia & 2,299 \\
Canadá & 29,623 \\
China & 6,485 \\
Estados Unidos & 40,460 \\
Rusia & 3,760 \\
\hline Total & 88,718 \\
\hline Fuente: www.fao.org/forestry
\end{tabular}

comercializadores de este bien en el mundo (sin incluir a Brasil). En total comercian más de 88,000 millones de dólares anualmente. El siguiente cuadro, ilustra claramente lo anterior.

De las seis naciones que aparecen en el cuadro 2, Estados Unidos es el productor y consumidor más importante, no sólo del grupo sino del planeta: con 40,460 millones de dólares de comercio se convierte, según datos de 1998, en el principal importador y el segundo exportador de productos forestales en el mundo. Le sigue Canadá, con un rango de casi 11 mil millones de dólares, aunque su balanza comercial refleja saldo positivo en este sector, hecho que no sucede con Estados Unidos. Como muestra el cuadro 2, la diferencia en la cantidad comercializadora entre los países es bastante evidente. Esto se debe a que la industria de los productos forestales de Canadá y de Estados Unidos está tecnológicamente más avanzada y puede talar y procesar madera en gran escala. Un dato que merece la atención es el de Rusia. Este país cuenta con la mayor superficie forestal del mundo, pero mantiene un pobre desempeño en comparación con Estados Unidos y Canadá. Rusia apenas alcanza el 9 por ciento del comercio forestal de Estados Unidos y el 12.7 por ciento del comercio de Canadá.

Otra de las características de este conjunto de países es el establecimiento de medidas regulatorias para la protección de los bosques, tales como regulaciones sobre la tala de árboles, la reforestación, las reservas naturales, los parques nacionales, etc. Especialmente China, donde la repoblación forestal del territorio ha sido definida como un deber común de la sociedad. De las características que los diferencian es que sólo Canadá, Rusia e Indonesia reflejan saldos positivos en su balanza 
comercial, mientras que para Estados Unidos, China y Australia son negativos ${ }^{5}$.

El resto de las siete economías presentan características más heterogéneas. Estas son: México, Chile, Vietnam, Singapur, Filipinas, Nueva Zelanda y Tailandia (no se incluyeron Taiwán ni Hong Kong por falta de datos). La particularidad de este grupo es que se trata de países moderadamente boscosos, cuya superficie en ese rubro oscila entre el 20 y 30 por ciento, con excepción de Singapur que sólo cuenta con el 3 por ciento de extensión forestal. México, por su mayor superficie territorial, es el que cuenta con un número mayor de hectáreas forestales en este grupo. Singapur por su parte, con sólo 0.003 por ciento de la superficie forestal de México, mantiene un comercio forestal con el exterior equivalente al 90 por ciento del comercio de México. Esto se debe a que Singapur importa grandes cantidades de productos madereros que después vuelve a e $x \quad p \quad o r t a r$, generalmente con valor agregado. México, por su parte, carece de una eficiente industria maderera. En este conjunto, Chile y Nueva Zelanda cuentan con un eficaz método de plantaciones forestales, de las cuales se extrae toda la madera necesaria para satisfacer su demanda. A su vez, su eficiente industria maderera fomenta las exportaciones, lo que le permite mantener un superávit comercial en estos productos. Por su parte Tailandia y Filipinas se caracterizan por la gran deforestación que se viene dando desde mediados del siglo XX, aunque a partir de la última década han aplicado programas que han detenido un poco esa tendencia.

\section{La deforestación en APEC}

La superficie forestal y el grado de deforestación son los parámetros que habitualmente se utilizan para el análisis de los bosques. Estos nos indican si el bosque se presenta como factor abundante dentro de un país, su situación actual, su uso y tratamiento, lo que se espera o se demanda de este bien, etc.

El siguiente cuadro nos muestra estas dos variables dentro de los países de APEC.

El cuadro 3 nos muestra que en general los países miembros de APEC, en la década de los noventa, mantuvieron una deforestación controlada. Sobresalen los casos de Filipinas, Indonesia, Malasia y México, por presentar tasas de deforestación mayores al uno por ciento de su cubierta forestal. Por el contrario, China, Nueva Zelanda, Vietnam y Estados Unidos, lejos de mostrar deforestación en sus bosques, aumentaron la extensión de éstos, gracias a la aplicación de programas de desarrollo sostenible, por medio de los cuales protegen y conservan los recursos forestales.

Por otro lado, Rusia, Canadá, Japón, Australia y Singapur no presentaron índices de deforestación, lo que significa que la cantidad extraída es la misma que se suple a través de plantaciones forestales ${ }^{6}$. 
Es importante señalar que la deforestación y degradación de los bosques no siempre se deben a causas directas del hombre (a través del aprovechamiento excesivo de madera industrial, de leña, o a la explotación inadecuada de los bosques de producción, junto con los sistemas de extracción poco apropiados), sino que además existen otros agentes de destrucción como los incendios, las plagas y enfermedades, el pastoreo excesivo, la expansión de las tierras agrícolas, la urbanización, los cambios climáticos, la contaminación atmosférica, etc. ${ }^{7}$ Estos factores, que propician la destrucción de los bosques muchas veces están fuera del alcance humano. Un ejemplo fue el llamado "Fenómeno del Niño", el cual trajo grandes sequías que provocaron múltiples incendios forestales en muchos países. Dentro de las economías miembro de APEC los bosques de Indonesia, México, Estados Unidos, Rusia y Australia se vieron afectados por esta causa. El último siniestro que enfrentó Australia fue la destrucción de más de medio millón de hectáreas de bosque a causa de un incendio que inició a finales 2001 y que pudieron controlar hasta la primera semana del 2002, hecho que nos indica que aun cuando los países industrializados cuentan con medidas más eficientes para enfrentar y controlar esos sucesos naturales, algunas veces se presentan casos de gran magnitud que sobrepasan la capacidad para controlar este tipo de catástrofes. El panorama se presenta con peores consecuencias en los países en vías de desarrollo y subdesarrollados, los cuales no cuentan con los medios ni con la preparación especializada para enfrentar este tipo de sucesos. En los últimos cinco años la política forestal en estos países ha comenzado a cambiar. En México por ejemplo, a partir de 1998, se han establecido estrategias y programas para controlar este tipo de sucesos, lo mismo sucedió en Tailandia e Indonesia a principios $\operatorname{del} 2000^{8}$.

Con el objeto de frenar la deforestación, en la década de los noventa, se pusieron en marcha, en algunos países de Asia-Pacífico, medidas de prohibición total o parcial a la explotación maderera de los bosques naturales. De los miembros de APEC, China, Nueva
Zelanda, Tailandia, Vietnam y Filipinas, impusieron esta medida. Para el año 2000, los resultados fueron muy diversos: Nueva Zelanda fue el único país donde la respuesta fue positiva, ya que suplió sus necesidades con la extracción de madera de bosques plantados. En los cuatro países restantes los resultados fueron negativos, ya que esta medida generó actividades ilegales que repercutieron en un fuerte golpe a la economía y en el medio ambiente. Ejemplos de lo anterior los tenemos en Tailandia y Filipinas, los cuales, de ser exportadores netos, pasaron a ser importadores de madera. Además, si observamos el cuadro 3, nos daremos cuenta que ambos países presentaron tasas de deforestación elevadas; es decir, no se detuvo la deforestación, puesto que propició la tala clandestina y en cambio sí se dañó su economía. China ${ }^{9}$ y Vietnam por su parte recurrieron a la importación, hecho favorable para países como Rusia que es exportador neto. China, que es un gran demandante de estos productos no satisface su consumo de una sola fuente, por lo que otros proveedores como Mongolia, reaccionaron restringiendo la exportación de madera aserrada a ese país, con el fin de proteger su industria y su demanda interna ${ }^{10}$

\section{La balanza comercial forestal de APEC}

Como se señala al principio, dentro de las economías de APEC se encuentran los mayores productores y comercializadores de productos forestales del mundo, actividad que genera dinamismo e ingresos tanto a las economías domésticas como a la economía internacional.

El comercio forestal (exportaciones más importaciones) de las economías de APEC suma en total 127,963 millones de dólares. Los países que más contribuyen al total son, Estados Unidos, Canadá, Japón, China, e Indonesia. Los países con menor comercio son: Brunei, Vietnam, Papua Nueva Guinea, Perú y Filipinas. Por otro lado, Estados Unidos, Japón, China, Canadá y Corea son los mayores importadores de estos productos. Mientras que los principales exportadores, de mayor a menor importancia, son: Canadá, Estados Unidos, Indonesia, Malasia y Rusia. 
Cuadro 4

Balanza comercial forestal de los miembros de APEC: 1998

\begin{tabular}{lcccc}
\hline Países & $\begin{array}{c}\text { Importaciones } \\
\text { millones de dólares }\end{array}$ & $\begin{array}{c}\text { Exportaciones } \\
\text { millones de dólares }\end{array}$ & $\begin{array}{c}\text { Total millones } \\
\text { de dólares }\end{array}$ & $\begin{array}{c}\text { Saldo millones } \\
\text { de dólares }\end{array}$ \\
\hline Inonesia & 975 & 5,115 & 6,091 & 4,139 \\
Australia & 1,498 & 801 & 2,299 & -696 \\
Canadá & 3,976 & 25,647 & 29,623 & 21,671 \\
China & 5,661 & 824 & 6,485 & $-4,837$ \\
Estados Unidos & 24,134 & 16,326 & 40,460 & $-7,808$ \\
Rusia & 752 & 3,007 & 3,760 & 2,255 \\
Nueva Zelanda & 309 & 1,418 & 1,727 & 1,108 \\
México & 1,470 & 444 & 1,914 & $-1,025$ \\
Singapur & 1,094 & 635 & 1,729 & -459 \\
Vietnam & 87 & 44 & 131 & -43 \\
Chile & 281 & 1,436 & 1,717 & 1,154 \\
Filipinas & 703 & 63 & 767 & -640 \\
Tailandia & 1,528 & 574 & 2,102 & -953 \\
Malasia & 930 & 3,951 & 4,881 & 3,021 \\
Brunei & 8 & 0 & 8 & -8 \\
Corea & 3,739 & 1,213 & 4,952 & $-2,526$ \\
Japón & 16,684 & 1,640 & 18,324 & $-15,044$ \\
P. Nueva Guinea & 10 & 368 & 378 & 358 \\
Perú & 179 & 43 & 222 & -136 \\
\hline total & 64,018 & 63,549 & 127,570 & -469 \\
\hline Fuente: www.fao.org/forestry/country & & & \\
Nota: no se incluye Taiwán y Hong kong por falta de datos & & & \\
& & & &
\end{tabular}

De los 19 países que aparecen en el cuadro 4, 12 de ellos manejan saldos negativos en su balanza. De estos, Japón, China, Corea, Brunei, Australia y en buena parte Estados Unidos satisfacen su demanda maderera con importaciones, con el objeto de conservar sus bosques, prefieren el costo económico al costo ambiental. Los más perjudicados en este tipo de decisiones son los países proveedores, ya que en su mayoría son los países subdesarrollados o en vías de desarrollo y que no cuentan con políticas forestales adecuadas ni con desarrollo sustentable que les permita recuperar la deforestación.

Un caso excepcional es Singapur, ya que al carecer de recursos forestales satisface sus necesidades de consumo a través del comercio exterior. Aunque recupera el 58 por ciento de este gasto gracias al valor agregado de sus exportaciones madereras. Cosa contraria sucede con Brunei, que con el 84 por ciento de superficie arbolada, se satisface casi completamente del exterior y como carece de industria maderera no le permite vender más allá de su demanda doméstica.

Otro caso que llama la atención es el de los tres países latinoamericanos de APEC: México, Chile y Perú, ya que presentan maneras muy diferentes de manejar sus recursos forestales. Para empezar, México y Perú manejan déficit en su balanza forestal, mientras que Chile tiene un saldo positivo de 1,154 millones de dólares, no obstante que sólo cuenta con el 24 por ciento de la superficie forestal de Perú y el 28 por ciento de la extensión forestal de México. Como se aprecia en el cuadro 3, Chile es el que presenta la tasa de deforestación más baja de este grupo, mientras que México la más alta. De este conjunto de países, el que comercia mayor cantidad de bienes madereros es México, pero sólo lleva una ventaja del 10 por ciento con relación a Chile. El valor de la producción forestal de México es de 69 por ciento menor al del Chile. Por otro lado, la baja participación del sector forestal en la economía peruana nos lleva a suponer que a pesar de la ventaja 
comparativa que tiene este país en el sector forestal, carece de un uso adecuado de los factores, ya que como se aprecia en las cifras del cuadro 4, éste resulta ineficiente, obsoleto y poco productivo. Situación muy similar a la de México.

Para países como Papua Nueva Guinea y Malasia, el ingreso obtenido a través del sector forestal contribuye fuertemente en su economía. Tailandia y Filipinas, por su parte sufren las consecuencias de una mala planificación y de carencia de medidas para proteger sus bosques, lo que los ha llevado a convertirse en importadores madereros.

A manera de conclusión es necesario señalar que a pesar de que dentro de los países miembros de APEC se encuentran la mayor superficie forestal del planeta y con ello los mayores comercializadores de este bien, en conjunto presentan déficit en el total de la balanza forestal, lo que nos indica que no se están aprovechando los recursos forestales correctamente. Además, con excepción de los países industrializados, los países que presentan saldo negativo en su balanza forestal son los mismos que manejan mayores tasas de deforestación en sus bosques. A esto hay que agregar que, de acuerdo con informes del Programa de Naciones Unidas para el Medio Ambiente (PNUMA), la demanda de recursos maderables presentará un aumento relativo precisamente en Asia. Este mismo informe señala que de continuar el actual manejo de los bosques, la reserva de madera durará menos de cuarenta años.

Ante tal pronóstico, es necesario un consenso intergubernamental entre los miembros de APEC para proteger esta industria de vital importancia, ya que la acción de los organismos no gubernamentales en pro de la biodiversidad del planeta no es suficiente. Es necesario establecer medidas por parte de organismos supranacionales como APEC para recuperar los bosques. Como se sabe, los bosques son un recurso renovable, a los que, por ignorancia e intereses mezquinos, no se les ha dado la importancia debida para preservarlos. $\mathrm{Al}$ no prestarles atención, se atenta contra ellos y se reduce la capacidad del planeta de absorber las emisiones de dióxido de carbono. No es suficiente con la protección de los bosques de los países desarrollados. Es urgente que se establezcan medidas dentro de APEC para generalizar en todos sus miembros la protección de las reservas forestales, su ampliación y su explotación racional con recursos tecnológicos y una industria eficiente.

\section{Notas}

1 www.apec.org y Perspectivas del medio ambiente 2000, página 8

2 2000, Ordenamiento ecológico territorial, SemarnatSemades.

3 www.fao.org/forestry

4 Ibídem

5 «Situación de los bosques del mundo2001»publicado por la FAO.

62001 World Bank Atlas

7 Perspectivas del medio ambiente 2000, página 38

8 «Situación de los Bosques del Mundo 2001» publicado por la FAO.

9 China implementó este programa a partir de 1998.

10 «Situación de los Bosques del Mundo 2001» publicado por la FAO

\section{Fuentes}

\section{www.apec.org}

www.fao.org/forestry/fo/country

www.fao.org/docrep/003/y099s/y0900s04.htm\#p1 0

PNUMA,2000, Perspectivas del medio ambiente mundial 2000,Ediciones Mundi-Prensa Libros, España.

Semarnat,2000, Ordenamiento ecológico territorial, Semarnat-Semades.

2001,World Bank Atlas

1998, Ministerio de Planificación y Cooperación de Chile, Balance de seis años de las políticas sociales 1990-1996. Editado por el Ministerio de Planificación y Cooperación de Chile.

1997, Vincent Jeffrey, Mohamed Rozali and Associates, Environment and Development, Harvard Institute for International Development, Institute of Strategic and Intenational Studies, Malaysia m:3 